\title{
RESPONSABILIDAD PENAL DE LAS PERSONAS JURÍDICAS $Y$ DERECHO ADMINISTRATIVO SANCIONADOR. ESPECIAL CONSIDERACIÓN DE CRITERIOS POLÍTICO-LEGISLATIVOS DE ATRIBUCIÓN DE RESPONSABILIDAD
}

CRIMINAL RESPONSIBILITY OF LEGAL PERSONS AND ADMINISTRATIVE CRIMINAL LAW. SPECIAL CONSIDERATION OF POLITICAL-LEGISLATIVE CRITERIA FOR THE ASSIGNMENT OF RESPONSIBILITY

Manuel Gómez Tomillo ${ }^{1}$ Universidade de Valladolid

\section{Resumen}

Nuestro trabajo examinará qué criterios de imputación de infracciones administrativas a personas jurídicas deben utilizarse en el Derecho administrativo sancionador, qué personas físicas podrían comprometer administrativamente a la persona jurídica y con qué requisitos. Estimamos central la repercusión que la real o potencial introducción de la responsabilidad penal de las personas jurídicas puede tener en el tratamiento de las infracciones administrativas, singularmente en lo que a la tipicidad concierne. Así, examinaremos si es posible acudir a la analogía para extender los criterios empleados en un sector del Derecho al otro.

\section{Palabras-clave}

Responsabilidad. Persona Jurídica. Criterios.

El presente trabajo forma parte del Proyecto de investigación DER 201123.072/JURI, financiado por el Ministerio español de Economía y Competituvidad, «Principio de precaución: proyección en el tratamiento jurídico-sancionatorio de organismos genéticamente modificados».

${ }^{1}$ Profesor Titular de Derecho penal. Acreditado a catedrático. Universidad de Valladolid. 


\begin{abstract}
Our work will examine what criteria of attribution of administrative infractions to legal persons should be used in administrative law, which natural persons could administratively compromise the legal entity and with what requirements. We consider central the repercussion that the real or potential introduction of the criminal responsibility of legal persons can have in the treatment of administrative infractions, especially as far as the suitability of a criminal type is concerned. Thus, we will examine whether it is possible to resort to analogy to extend the criteria used in one sector of the law to the other.
\end{abstract}

Keywords

Responsibility. Legal person. Criteria

\title{
1. Introducción.
}

Como es conocido, en los ordenamientos jurídicos en los que existe la distinción entre Derecho penal y Derecho administrativo sancionador, en esta última rama del ordenamiento jurídico, desde hace muchos años, es habitual la posibilidad de sancionar a las personas jurídicas². En los países europeos continentales, esa

${ }^{2}$ Concretamente, en el caso español, el artículo 130.1 de la Ley 30/1992 de 28 de noviembre de RJAPyPAC dispone que «Sólo podrán ser sancionadas las personas físicas y jurídicas que resulten responsables de los mismos aun a título de simple inobservancia». En relación con ello, apenas es precisa la cita de la casi clásica STC 246/1991 de 19 de diciembre. Sobre tal sentencia, puede verse, además de la bibliografía que citaremos, el solvente comentario que en su día efectuó B. Lozano Cutanda, «La responsabilidad de la persona jurídica en el ámbito sancionador administrativo (a propósito de la STC 246/1991», $R A P 129$, 1992, quien, entre otras cuestiones, analiza los precedentes jurisprudenciales, así como los derechos que se estima pueden disfrutar las personas jurídicas en estos y otros procedimientos; vid., de la misma autora la voz «Persona jurídica, sujeto activo responsable de las infracciones administrativas», Diccionario de sanciones administrativas (B. Lozano Cutanda, dir.), Madrid, 2010, pp. 601 y ss. 
responsabilidad administrativa de las personas jurídicas ha sido habitualmente anterior en el tiempo a la responsabilidad penal que progresivamente se viene implantando en múltiples sistemas positivos (con la muy notable excepción alemana) ${ }^{3}$. Ello ha servido para que la teoría de la responsabilidad de las personas jurídicas haya alcanzado un notable alcance, siguiendo un camino inverso del habitual. Históricamente lo normal ha sido la influencia del Derecho penal sobre el Derecho administrativo sancionador, ante la evidencia de su común origen histórico y su más que probable unidad esencial. En este particular campo, por el contrario, el Derecho administrativo sancionador ha tenido la oportunidad de ir por delante, allanando el camino a una potencial admisión de la responsabilidad penal de las personas jurídicas ${ }^{4}$.

${ }^{3}$ Aunque la cuestión ahora mismo desborda el marco trazado para nuestro trabajo, quizá sea interesante poner de manifiesto en que el fenómeno del Derecho administrativo sancionador no es tan universal como pensamos, toda vez que en numerosos países de nuestro entorno jurídico y cultural sigue siendo algo excepcional; dejando al margen a los países anglosajones y, singularmente a los Estados Unidos de América, en Europa hay múltiples países en los que no hay una verdadera potestad sancionadora de la Administración, con un predominio casi absoluto del Derecho penal, como es el caso de Dinamarca o Suecia, por poner sólo algún ejemplo; en general, puede verse el estudio de P. Rando Casermeiro, La distinción entre el Derecho penal y el Derecho administrativo sancionador. Un análisis de política jurídica, Valencia, 2010, pp. 69 y ss. Combate la idea conforme a la cual no hay propiamente un Derecho administrativo sancionador en el sistema jurídico angloamericano A. Betancor, «Derecho administrativo sancionador en el sistema jurídico británico: Regulatory enforcement and sanctions Act», Revista General de Derecho Administrativo 19, 2009, passim.

${ }^{4}$ Lo que es muy expresivo de la identidad que en cuanto a su naturaleza jurídica presentan ambos sectores del ordenamiento jurídico. Sobre esta cuestión, permítasenos remitirnos a M. Gómez Tomillo; I. Sanz Rubiales, Derecho administrativo sancionador. Parte general, 3 ed., 2013, Cap. 1. 
En el contexto apuntado, nuestro trabajo examinará qué criterios de imputación de infracciones administrativas a personas jurídicas deben utilizarse en el Derecho administrativo sancionador, qué personas físicas podrían comprometer administrativamente a la persona jurídica y con qué requisitos. A tal efecto, debe considerarse que, a diferencia de lo que ocurre en Alemania, donde la Ordnungswidrigkeitengesetz incluye una amplia parte general aplicable, en principio, a toda infracción administrativa, en la mayor parte de los sistemas se carece de un tratamiento positivo tan detallado, ni en general en lo que a las infracciones administrativas respecta, ni en particular en lo que a los criterios de imputación de responsabilidad concierne $e^{5}$. Por consiguiente, estimamos central la repercusión que la real o potencial introducción de la responsabilidad penal de las personas jurídicas puede tener en el tratamiento de las infracciones administrativas, singularmente en lo que a la tipicidad concierne. Así, examinaremos si es posible acudir a la analogía para extender los

${ }^{5}$ En el caso español, por una parte, el artículo 130 de la Ley 30/1992 contiene una mera declaración que posibilita la exigencia de responsabilidad sancionatoria administrativa a las personas jurídicas, insuficiente sin el complemento de las leyes sectoriales. Por otra parte, el citado precepto no establece base alguna para efectuar la imputación de tal responsabilidad. Así lo indica, por ejemplo, la STS de 31 de diciembre de 2008, Sala de lo contencioso-administrativo (RJ2009\465), Fto. Jco. 6o, con cita del artículo 130.3 de la misma Ley 30/1992. La situación cursa paralela a la característica del Derecho penal, en la que, como es conocido, existe un sistema de numerus clausus de delitos susceptibles de ser imputados a las personas jurídicas. En general, sobre esto último, vid., por ejemplo, A. Galán Muñoz, «La responsabilidad penal de la persona jurídica tras la reforma de la LO 5/2010: entre la hetero-y la autorresponsabilidad», Nuevos instrumentos jurídicos en la lucha contra la delincuencia económica y tecnológica, (C.M. Romeo Casabona; F. Flores Mendoza Eds.), 2012, pp. 485 y ss. 
criterios empleados en un sector del Derecho al otro. Obviamente, en los países anglosajones no hay un Derecho administrativo sancionador consolidado. Sin embargo, como es conocido, en ellos está plenamente aceptada la posibilidad de sancionar a las personas jurídicas. Desde esa perspectiva, los criterios allí desarrollados pueden ser extremadamente útiles en el contexto europeo continental.

El tema planteado no es irrelevante, si se considera la alta capacidad punitiva de las sanciones administrativas, frecuentemente superior, incluso, a la característica de las penas y el considerable número de ordenamientos jurídicos que progresivamente van superando el brocárdico Societas delinquere non potest.

Con ello no se agotan, ni mucho menos, los potenciales efectos que el reconocimiento de la responsabilidad penal de las personas jurídicas puede tener en el campo del Derecho administrativo sancionador. Por ejemplo, quedaría pendiente el examen de todas las cuestiones conexas con la culpabilidad de las personas jurídicas, incluidos los problemas relativos a la exigencia de dolo o, alternativamente, de imprudencia en estos últimos casos. Sin embargo, no resulta posible en un artículo de estas características abordar con toda su extensión tal problemática que dejamos para otra ocasión ${ }^{6}$.

Admitida, pues, la posibilidad de sancionar administrativamente a las personas jurídicas, se acepte o no su responsabilidad penal, procede examinar los criterios para atribuir responsabilidad a tales sujetos. Sin que podamos aspirar ahora a agotar la cuestión de la imputación objetiva de una infracción administrativa (o de un delito) a una persona jurídica, entendemos que para ello es

\footnotetext{
${ }^{6}$ Algunas cuestiones hemos examinado ya M. Gómez Tomillo; I. Sanz Rubiales, Derecho administrativo sancionador. Parte general, Teoría general y práctica del Derecho penal administrativo, 3a ed., 2013, Cap. 19.
} 
preciso que concurran dos requisitos. Ambos, resultarían imprescindibles, independientemente de que estemos en el ámbito estricto del Derecho penal o, alternativamente, del Derecho administrativo sancionador. En primer lugar, la actuación (o la omisión de hacerlo) de una o más personas físicas, lo que en la doctrina alemana se viene llamando hecho de conexión o Anknüpfungstat ${ }^{7}$. En

${ }^{7}$ Vid., en relación con el derecho penal español vigente, S. Bacigalupo Sagesse, Comentarios al Código Penal (M. Gómez Tomillo, dir.), 2a ed., Valladolid, 2011, art. 31 bis, a); de la misma autora «Los criterios de imputación de la responsabilidad penal de los entes colectivos y de sus órganos de gobierno (arts. 31 bis y 129 CP)», La Ley 7541, 2011, p. 10; de la misma autora «La responsabilidad penal de los entes colectivos: societas delinquere non potest», Libro homenaje al Profesor Luis Rodríguez Ramos, Valencia, 2013, p. 33; J.M. Zugaldía Espinar, La responsabilidad penal de empresas, fundaciones y asociaciones, Valencia, 2008, especialmente p. 350; del mismo autor, «Societas delinquere potest (Análisis de la reforma operada por la LO 5/2010 de 22 de junio)», La Ley penal, 76, 2010, p. 2; B. del Rosal Blasco, «La delimitación típica de los llamados hechos de conexión, en el Nuevo artículo 31 bis no 1 del Código Penal», CPC 103, 2011, p. 53; M. Bajo Fernández, «Vigencia de la responsabilidad penal de las personas jurídicas en el derecho sancionador español», Tratado de responsabilidad penal de las personas jurídicas, 2012, p. 34; ya antes, por muchos, H-J. Hirsch, «La cuestión de la responsabilidad penal de las asociaciones de personas», ADPCP 1993, p. 1106. A. Nieto Martín, La responsabilidad penal de las personas jurídicas: un modelo legislativo, 2008, p. 165; M.J. Guardiola Lago, Responsabilidad penal de las personas jurídicas y alcance del artículo 129 del Código Penal, Valencia, 2004, pp. 68-9, donde subraya que es el mecanismo que permite afirmar el establecimiento de un tipo de responsabilidad directa de la persona jurídica. Se ha llegado a decir que ese hecho de conexión constituye «de algún modo» una condición objetiva de punibilidad, M. Bajo Fernández; S. Bacigalupo, Derecho penal económico, 2a ed., Madrid, 2010, Cap. V, 70; vid., asimismo, G. Dannecker, «Zur Notwendigkeit der Einführung kriminalrechtlicher Sanktionen gegen Verbände», GA 2001, p. 119; vid., en general, las referencias que proporciona G. Heine, Die strafrechtliche Verantwortlichkeit von Unternehmen, von individuellem Fehlverhalten zu kollectiven Fehlentwicklungen, insbesondere bei Grossrisiken, 1995, p. 231 relativas al hecho de conexión como tal condición objetiva 
segundo lugar, la imputación de un delito a una persona jurídica requiere que ese hecho de conexión aparezca externamente como un hecho de empresa, que sólo tenga sentido en ese contexto social. Examinaremos separadamente ambos requisitos.

\section{El hecho de conexión.}

\subsection{La exigencia del hecho de conexión como requisito de imputación.}

En cuanto al hecho de conexión entiendo que es preciso que una persona física, o una pluralidad de ellas, haya actuado o dejado de hacerlo. Desde nuestra perspectiva, se trata de una exigencia insoslayable ${ }^{8}$. Por un lado, es claro que sin esa actuación activopositiva u omisiva de la persona física nunca habrá qué imputar a una persona jurídica que por sí misma no puede actuar. Por otro, el hecho de conexión resulta un elemento imprescindible cara a la delimitación

de punibilidad (aunque este autor habla de desvalor de conexión externo -externen Anknüpfungsunwerte). En sentido crítico, vid. B. Feijoo Sánchez, «La responsabilidad penal de las personas jurídicas», Estudios sobre las reformas del Código Penal operadas por las LO 5/2010 de 22 de junio y 3/2011, de 28 de enero (J. Díaz Maroto, dir.), 2011, p. 103; del mismo autor, «Las características básicas de la responsabilidad penal de las personas jurídicas en el Código Penal español», Tratado de responsabilidad penal de las personas jurídicas, 2012, pp. 74 y ss. Entre la doctrina administrativista vid. M.J. Gallardo Castillo, Los principios de la potestad sancionadora. Teoría y práctica, 2008, p. 209, con cita expresa de la teoría del órgano en Derecho administrativo; A. Nieto, Derecho administrativo sancionador, op. cit., p. 393, con idéntica referencia, p. 406 y 411 y ss. analizando la cuestión de la responsabilidad administrativa de administraciones públicas infractoras.

${ }^{8}$ Dejamos al margen que se trata de un requisito que, desde el punto de vista del Derecho penal positivo español, es claro; al respecto, vid. nuestro trabajo «Imputación objetiva y culpabilidad en el Derecho penal de las personas jurídicas», Revista Jurídica de Castilla y León 25, 2011, 2.2. 
del Derecho penal o administrativo sancionador aplicable o, lo que es lo mismo, desde el punto de vista de la competencia de los tribunales. No se trata de una cuestión menor, si se considera, como se ha destacado acertadamente, que una persona jurídica puede tener su sede en Europa, su producción en Asia y comercializar sus productos en América9.

Ciertamente, una sólida corriente de opinión científica ha criticado la necesidad de requerir en todo caso tal hecho. Se argumenta, por ejemplo, que con su exigencia no se solucionan algunos de los casos más problemáticos, concretamente, aquéllos en los que no se puede identificar al autor físico concreto del hecho, hipótesis en las que no se podría sancionar a la persona jurídica ${ }^{10}$. Sin embargo, reiteramos que resulta ineludible la exigencia de un hecho de conexión en la medida en que, lógicamente, sin éste tampoco hay hecho de la persona jurídica misma. Por otra parte, el obstáculo se

${ }^{9}$ A. Galán Muñoz, «La responsabilidad penal de la persona jurídica tras la reforma de la LO 5/2010... », op. cit., p. 507, quien con mucha razón subraya el riesgo de que una empresa se implante en países con un sistema más tolerante, de modo que la responsabilidad penal de las personas jurídicas pueda constituirse en una suerte de competencia desleal. La cuestión de la aplicación espacial del Derecho penal de las personas jurídicas es, pues, una cuestión absolutamente central. Puede ser interesante subrayar que en Italia, una persona jurídica que tiene su sede en ese país responde administrativamente por un delito cometido por sus filiales en el extranjero si no se inicia un procedimiento penal en el lugar en el que se encuentran radicadas (a favo de incorporar tal previsión al Derecho inglés, vid. James Gobert; Maurice Punch, Rethinking corporate crime, 2003, pp. 109-110). En España, por el contrario, se carece de previsiones al respecto.

${ }^{10}$ Vid. L. Zúñiga Rodríguez, Bases para un modelo de imputación de responsabilidad penal de las personas jurídicas, 2001, pp. 236 y, sobre todo, 245; vid., asimismo, amplias referencias en J.M. Zugaldía Espinar, La responsabilidad penal de empresas..., op. cit., pp. 147 y ss.; C. Gómez-Jara Díez, La culpabilidad penal de la empresa, Madrid, Barcelona, 2005, p. 158. 
difumina si, como haremos aquí, aceptamos que cualquier individuo enmarcado en la estructura social puede determinar la responsabilidad de la sociedad misma. Cuestión diversa es que en determinadas circunstancias deba procederse a absolver a la persona jurídica, cuando, por ejemplo, concurran dudas sobre si el sujeto no identificado que lo llevó a cabo actuó o no dentro del marco social ${ }^{11}$. Pero el hecho mismo tiene que existir.

Desde otra perspectiva, se aduce en contra de la exigencia de un hecho de conexión que en determinadas ocasiones no se puede imputar la lesión del bien jurídico sino a una multiplicidad de decisiones defectuosas en el seno de la empresa, las cuales por sí mismas ni merecen el reproche del Derecho, ni incluso son evitables en el seno de grandes empresas ${ }^{12}$. Sin embargo, el hecho de conexión no tiene por qué ser concebido en términos unitarios. Cabe un hecho de conexión plural, fragmentado o, incluso, atomizado, lo que no obsta a que ese hecho siga existiendo. Por otra parte, también en el Derecho

${ }^{11}$ La ruptura de la balsa que aloja residuos industriales puede deberse a un irracional sabotaje de un sujeto ajeno a la empresa o, por el contrario, a la acción u omisión descuidada de un trabajador que, por las circunstancias del caso concreto, no se puede individualizar. En el primer caso, en principio, no habría hecho de conexión (podría haber una omisión imprudente, por ejemplo, de las medidas de seguridad exigibles). En el segundo sí. Cuando el juez dude sobre si nos encontramos ante la primera hipótesis o ante la segunda, si no se tiene claro, pues, si hubo o no hecho de conexión, debe absolver, puesto que el principio in dubio pro reo, inequívocamente también opera en el marco del Derecho penal de las personas jurídicas.

${ }^{12}$ Vid. G. Heine, Die strafrechtliche Verantwortlichkeit von Unternehmen, op. cit., p. 207; N. Bosch, Organisationverschulden in Unternehmen, 2002, pp. 55-6, quien hace referencia a hipótesis de déficits de conciencia y prevención del riesgo que se van acumulando a lo largo de los años y que no se deben a una concreta decisión; J. Gobert; M. Punch, Rethinking corporate crime, 2003, pp. 82 y ss. especialmente p. 84. 
penal de las personas físicas se dan fenómenos análogos en el marco de la codelincuencia o, en el Derecho administrativo sancionador, existe la responsabilidad conjunta, solidaria o subsidiaria ${ }^{13}$. Finalmente, con frecuencia se podrá aislar a un sujeto o grupo de sujetos concretos sobre los que gravite una posición de garantía, en la medida en que tengan el deber jurídico de evitar, precisamente, ese cúmulo de decisiones defectuosas.

Por último, en contra del hecho de conexión no cabe argumentar que su exigencia equivale a una responsabilidad de la persona jurídica de naturaleza vicarial o por hechos de otro ${ }^{14}$,

${ }^{13}$ Vid. nuestro Derecho administrativo sancionador. Parte general, op. cit., Caps. 22 a 24 .

${ }^{14} \mathrm{El}$ reproche es muy frecuente; vid., por muchos, J.G. Fernández Teruelo, «La responsabilidad penal de las personas jurídicas en el Código Penal español: una visión crítica», Revista Jurídica de Castilla y León 25, 2011, p. 57. De heteroresponsabilidad habla la Circular 1/2011, p. 31, para posteriormente decir que, si bien no es responsabilidad independiente sí lo es autónoma y en otro momento de responsabilidad vicarial (p. 33), lo que, entiendo, no es exacto. La misma expresión es empleada por V. Gómez Martín, Comentarios al Código Penal (M. Corcoy Bidasolo; S. Mir Puig, dirs.), Valencia, 2011, art. 31 bis, p. 131. Amplias referencias en cuanto a ambos modelos, responsabilidad vicarial y responsabilidad independiente, J.M. Zugaldía Espinar, La responsabilidad penal de empresas..., op. cit, pp. 140 y ss.; A. Nieto Martín, Responsabilidad penal de las personas jurídicas..., op. cit., pp. 102 y ss., R. Robles Planas, «¿Delitos de personas jurídicas?», InDret 22006, pp. 5 y ss.; J.L. Díez Ripollés, «La responsabilidad penal de las personas jurídicas. Regulación española», InDret 1-2012, p. 6; A. Galán Muñoz, «La responsabilidad penal de la persona jurídica tras la reforma de la LO 5/2010... », op. cit., pp. 509 y ss.; crítico con el modelo vicarial; J.M. Silva Sánchez, «La responsabilidad penal de las personas jurídicas en el Convenio del Consejo de Europa sobre cibercriminalidad», Cuadernos de Derecho Judicial 9, 2002, pp. 126 y ss.; en la misma línea crítica C. Gómez-Jara Díez, «Autoorganización empresarial y autorresponsabilidad empresarial», RECPC 08-05, pp. 1 y ss. En los Estados Unidos, como es conocido, se mantiene ampliamente la idea de que la responsabilidad de las 
incompatible con el principio de personalidad. Debe entenderse que, siendo un requisito imprescindible por su especial naturaleza la actuación de una persona física, lo injusto es propio de la persona jurídica. Parece claro que también en el Derecho penal de las personas físicas se atribuyen hechos de unos sujetos a otros que no los han cometido directo-corporalmente, como ocurre con la coautoría, la autoría mediata, o las actuaciones en nombre de otro ${ }^{15}$, ámbitos en los que nadie habla de responsabilidad vicarial. Con razón, se ha hablado de una especie de accesoriedad de lo injusto de la persona jurídica con respecto a la acción $\mathrm{u}$ omisión de la persona física ${ }^{16}$. Aunque no

personas jurídicas es vicarial, vid. ahora sólo Richard S. Gruner, Corporate criminal liability and prevention, New York, (updated 2010), § 1.02; Barry J. Pollack, «Time to stop living vicariously: a better approach to corporate criminal liability», $46 \mathrm{Am}$. Crim. L. Rev. 1393, particularmente, 1395-6, con consideraciones críticas; J. Gobert; M. Punch, Rethinking corporate crime, op. cit. (n. 18), pp. 55 y ss.; C. Wells, Corporations and Criminal Responsibility, 1993 pp. 97 y ss., especialmente en lo que respecta a la evolución histórica y donde subraya las muchísimas limitaciones que esa responsabilidad vicarial experimenta en el Derecho inglés vigente, sobre todo por la conexión entre responsabilidad vicaria y responsabilidad objetiva (strict liability).

${ }^{15}$ En sentido semejante se expresa K. Tiedemann, «Die "Bebüssung" von Unternehmen nach dem 2 Gesetz zur Bekämpfung der Wirtschaftskrimimalität», $N J W 41,1988$, p. 1171; vid., asimismo, la sintética exposición y referencias que efectúa G. Trug, «Zu den Folgen des Einführung eines Unternehmensstrafrechts», Wistra 7, 2010, p. 243; crítico se muestra G. Heine, Die strafrechtliche Verantwortlichkeit von Unternehmen, op. cit., p. 243, fundamentalmente en lo relativo a la coautoría, pero no tanto en lo que a la autoría mediata se refiere.

${ }^{16} \mathrm{La}$ idea aparece repetidamente en la literatura alemana, vid., sólo por ejemplo, $\mathrm{N}$. Bosch, Organisationverschulden..., op. cit., p. 58, pp. 60 y ss., etc.; J.M. Silva Sánchez, «La responsabilidad penal de las personas jurídicas...», op. cit.., p. 132; Zugaldía Espinar en relación con el Proyecto de reforma del Código Penal, y en el marco de la imputación objetiva, sostenía que hay una accesoriedad mínima del delito de la persona jurídica con respecto a la persona física, toda vez que la existencia 
podemos entrar en detalles ahora mismo, desde nuestra perspectiva, lo injusto de las personas jurídicas es un injusto propio, no derivado, de naturaleza compleja ${ }^{17}$. Deriva de la conjunción, de la sinergia de la actuación de la persona física con las especiales posibilidades estructurales y medios de la persona jurídica efectivamente utilizados e implica necesariamente la lesión o puesta en riesgo de bienes jurídicos. Se trata de una situación muy próxima, si bien no idéntica, a la característica de la coautoría ${ }^{18}$.

de delito en la primera es independiente de que la persona física, por ejemplo, actúe sin dolo o sin imprudencia (La responsabilidad penal de las empresas..., op. cit., p. 145, donde ejemplifica con el supuesto en el que el sujeto actuante fue defectuosamente informado por parte del que tenía el poder de dirección). De accesoriedad media habla B. Feijoo Sánchez, «La responsabilidad penal de las personas jurídicas», op.cit., p. 90; el mismo autor, «Las características básicas de la responsabilidad penal de las personas jurídicas en el Código Penal español», op. cit., p. 87; accesoriedad limitada expresa V. Gómez Martín, Comentarios al Código Penal..., op. cit., p. 135.

${ }^{17}$ Diversas posiciones en la materia se encuentran bien sintetizadas en J.L. Díez Ripollés, «La responsabilidad penal de las personas jurídicas. Regulación española», op. cit., pp. 7-8; particularmente sólido, aunque en línea diversa de la defendida en este trabajo, vid. J.L. de la Cuesta Arzamendi, «Responsabilidad penal de las personas jurídicas en el Derecho español», Revue électronique de l'AIDP, 2011, especialmente A-05: 07.

${ }^{18}$ Sobre el particular, vid. nuestra Introducción a la responsabilidad penal de las personas jurídicas, Valladolid, 2010, Cap. 13, apartados 4 y 5; Tiedemann afirma que la persona física realmente actuante se transforma, en cierta manera, en coautor; Tiedemann, K., «Responsabilidad penal de las personas jurídicas», Anuario de Derecho penal 1996 (http://www.unifr.ch/ddp1/derechopenal/anuario/an_1996_07.pdf), op. cit., 22; habla de sistema de doble autoría E. Bacigalupo, «Responsabilidad penal y administrativa de las personas jurídicas y programas de "compliance” (A propósito del Proyecto de reformas del Código Penal de 2009)», La Ley 7442, 2009, p. 2; crítico hacia la idea de la coautoría vid. B. Feijoo Sánchez, Sanciones para empresas por 
En ese contexto, en la literatura científica alemana se plantea la cuestión de si debe existir vínculo de causalidad entre el hecho de conexión y el resultado lesivo ${ }^{19}$. Desde nuestra perspectiva, en las infracciones de resultado, imputándose a la persona jurídica un hecho activo positivo, la respuesta debe ser afirmativa. Ciertamente, tal afirmación debe ser matizada en la medida en que la acción individual habitualmente se sumará a un complejo cúmulo de factores. Con razón indica HEINE que en estos casos el trastorno social consecuencia de un hecho social delictivo ya no aparece como el resultado dominable por la voluntad de un autor, sino el resultado de complejos procesos de acumulación y efectos sinérgicos ${ }^{20}$. Por el contrario, en el caso de las omisiones, el análisis debería decir previamente si aquella conexión de causalidad es exigible en este último grupo de delitos o infracciones administrativas. Más bien entendemos que lo que hay que acreditar en este último caso es la conexión entre el resultado lesivo y el foco de

delitos contra el medio ambiente (Presupuestos dogmáticos y criterios de imputación para la intervención del Derecho penal contra las empresas), Madrid, 2002, pp. 78 y ss.

${ }^{19}$ Vid., por todos, G. Heine, Die strafrechtliche Verantwortlichkeit von Unternehmen, op. cit., pp. 226, 292, entre otras.

${ }^{20} \mathrm{G}$. Heine, Die strafrechtliche Verantwortlichkeit von Unternehmen, op. cit., p. 292; mientras que en las pp.ss. desarrolla sus criterios de conexión del riesgo empresarial y el resultado en cuyos detalles no podemos detenernos; ampliamente, vid. N. Bosch, Organisationverschulden in Unternehmen..., op. cit., pp. 81 y ss. 
riesgo sobre el que era garante el omitente ${ }^{21}$. Nada diverso, pues, del caso de los delitos de omisión cometidos por personas físicas ${ }^{22}$.

\subsection{Personas físicas con capacidad de comprometer penal o administrativamente a una persona jurídica.}

Aceptada la necesidad de un hecho de conexión, resulta central delimitar quién en el contexto organizativo puede con su conducta, activa u omisiva, determinar la responsabilidad supraindividual.

${ }^{21}$ Desbordaría los límites de este trabajo proceder a examinar la específica problemática de la causalidad en las infracciones y delitos de comisión por omisión. Como es conocido, en ese específico ámbito se suele hablar de causalidad hipotética, la cual equivale a la exigencia de que la acción omitida hubiese evitado el resultado con una probabilidad rayana en la certeza (vid. H-H. Jescheck, Tratado..., op. cit., p. 563; en el marco específico de las infracciones administrativas, vid. E. Göhler, Ordnungswidrigkeitengesetz, op. cit., § 8, 3 a). La posiciones todavía hoy dominantes en la materia expuestas en el texto presentan el problema de que el Derecho penal, e igualmente el Derecho administrativo sancionador, no debe acudir para llegar a sus conclusiones a lo que potencialmente hubiese podido ocurrir, esto es, a juicios hipotéticos, donde siempre se presenta una imposibilidad de prueba, sino a lo que efectivamente acaeció, donde las cosas se presentan de manera matizadamente distinta. Así, en la actualidad, surgen otras posiciones que todavía podemos calificar como minoritarias en las que se exige que sea el foco de peligro el que haya causado efectivamente y sin duda los correspondientes resultados típicos: vid., sólo en la literatura científia en español: E. Gimbernat Ordeig, Comentarios al Código Penal, t. I, (Edersa), pp. 38 y ss.; C. Romeo Casabona, «Los delitos de comisión por omisión: delimitación, insuficiencias y perspectiva político criminal», Politica criminal y reforma pena. Homenaje al Profesor Dr. D. Juan del Rosal, 1993, p. 936.

${ }^{22}$ Los delitos y las infracciones administrativas de omisión imputables a las personas jurídicas plantean una problemática específica en la que no nos podemos detener; nos remitimos a nuestro trabajo Introducción a la responsabilidad penal de las personas jurídicas, op. cit., Cap. 7. 
Se trata de una cuestión muy dependiente de las soluciones que se adopten en el Derecho positivo. Las posibilidades son, al menos, tres.

1.- Si hay expresa previsión legal, obviamente, debe aplicarse. Sin embargo, no es habitual que las leyes administrativas prevean tales cuestiones, dejándolas en manos del aplicador del Derecho, sin más ${ }^{23}$. 2.- Si hay responsabilidad penal de las personas jurídicas, debe aplicarse ese modelo por analogía. A tal efecto, partimos de dos ideas. Por un lado, la identidad en cuanto a su naturaleza jurídico del Derecho penal y administrativo sancionador. Por otra, la inaplicabilidad de la prohibición de analogía, toda vez que el razonamiento analógico en este caso nunca supodrá una expansión de la responsabilidad sobre lo previsto en la Ley, toda vez que no existe esta última.

3.- Si no hay ni lo uno ni lo otro, debe optarse homogéneamente por alguno de los modelos teóricos de imputación de la responsabilidad diseñados esencialmente por la doctrina científica penalística. Éstos son, esencialmente tres.

En primer lugar, el modelo aquí defendido se corresponde básicamente con el estándar respondeat superior característico del Derecho penal de las personas jurídicas norteamericano ${ }^{24}$. Éste

${ }^{23}$ Atítulo de ejemplo, en España no se puede estimar que la Ley 30/1992 de 26 de noviembre de Régimen Jurídico de las Administraciones públicas y Procedimiento Administrativo Común solucione el problema.

${ }^{24}$ En los Estados Unidos se adopta habitualmente el modelo del texto; vid., por ejemplo, Richard S. Gruner, Corporate criminal liability and prevention, op. cit., § 2.03, 2-20; Kathleen B. Brickey, Corporate criminal liability, 2 ed., 1992, § 3.01. En Alemania, vid. sobre el modelo K. Tiedemann, «Die "Bebüssung”... », op. cit., p. 1172, con referencias a la jurisprudencia del Tribunal Constitucional alemán; de 
habitualmente requiere la presencia de tres requisitos ${ }^{25}$ : 1.- La comisión de un hecho punible por parte de un empleado de la empresa. 2.- Que el hecho se ejecute en el ejercicio de su actividad y en su seno (se suele utilizar la expresión within the scope of his employment) y no como mera persona privada ${ }^{26}$. 3.- Que el hecho se lleve a cabo con

alguna forma es preconizado de lege ferenda, por ejemplo, por G. Dannecker, «Zur Notwendigkeit der Einführung kriminalrechtlicher Sanktionen gegen Verbände...», op. cit., sobre todo p. 118, quien, sin embargo, subraya que cuando se trata de actuaciones de personas por debajo del nivel de dirección debería considerarse tan sólo una infracción administrativa (p. 122).

Entiendo que es el modelo que en España y dentro de la doctrina administrativista propugna M. Rebollo Puig, Potestad sancionadora, alimentación y salud pública, Madrid, 1989, p. 769 y, sobre todo, 771; B. Lozano Cutanda, «La responsabilidad de la persona jurídica en el ámbito sancionador administrativo», op. cit., particularmente pp. 227-228; P. Mayor Menéndez, «Sobre la responsabilidad conjunta de las personas jurídicas y sus administradores en el Derecho administrativo sancionador (especial referencia al Mercado de Valores», REDA 87, 1995, p. 352. En la doctrina penalista, vid. L. Zúñiga Rodríguez, Bases para un modelo de imputación de responsabilidad, op. cit., p. 235, cuando sostenía como actuación de una persona jurídica todas las conductas de los socios o componentes de la organización, que actuasen para la empresa que desencadena en riesgos evitables para los bienes jurídicos; en los últimos tiempos, O. Artaza Varela, La empresa como sujeto de imputación de responsabilidad penal, 2012, pp. 84 y ss.

${ }^{25}$ Por todos, vid. M. Kremnitzer, K. Ghanayim, «Die Strafbarkeit von Unternehmen», $Z S t W, 113,2001$, pp. 547-9, con expresión de posiciones críticas; en el sistema estounidense resulta casi un topico: las referencias son inagotables, vid., por ejemplo, Richard S. Gruner, Corporate criminal liability and prevention, op. cit., § 2.03, 2-20, especialmente, en cuanto al sistema federal; Pamela H. Bucy, «Why Punish? Trends in Corporate Criminal Prosecutions», 44 Am Crim. L. Rev. 1287 (2007), especialmente 1289 donde se revisan los estandares legales tradicionales en la materia; se aproxima el modelo austriaco, vid. R. Robles Planas, « $i$ Delitos de personas jurídicas?», op. cit., pp. 12-13.

${ }^{26}$ Vid. Kathleen B. Brickey, Corporate criminal liability, op. cit.§ 3.01, quien se encarga de subrayar que la idea de que el hecho se lleve a cabo dentro del alcance de 
la intención de favorecer a la empresa (donde se suele aceptar que el sujeto obre también con la intencionalidad de beneficiarse él mismo) ${ }^{27}$. Entre las ventajas que presenta el sistema se encuentra el que no es preciso aislar la concreta responsabilidad del sujeto físico que llevó a cabo materialmente el comportamiento punible, cuando precisamente uno de los argumentos empleados a favor de la responsabilidad de las personas jurídicas radica en la dificultades de prueba asociadas a los hechos llevados a cabo en complejas estructuras sociales ${ }^{28}$. $\mathrm{Al}$ margen de ello, en la literatura norteamericana se señalan, al menos, tres razones que apoyan este modelo. Por una parte, el empleado que actúa

su trabajo se limita a exigir que el hecho tenga que ver con el desarrollo del empleo o relacionado con él; J. Gobert; M. Punch, Rethinking corporate crime, op. cit., p. 57.

${ }^{27}$ Vid. Kathleen B. Brickey, Corporate criminal liability, op. cit. $§ 4, .02$, donde refleja algun supuesto excepcional en la jurisprudencia estadounidense que ha rechazado tal elemento generalmente admitido; J. Gobert; M. Punch, Rethinking corporate crime, op. cit., p. 57; no obstante, en el derecho inglés no se requiere tal intención (vid., por ejemplo, p. 78). Sobre la importancia del criterio de la actuación en interés de la persona jurídica, vid. S. Bacigalupo, Responsabilidad penal de las personas jurídicas, 1998, p. 396-7; H. Achenbach, «Sanciones con las que se pueden castigar a las empresas y a las personas que actúan en su nombre en el Derecho alemán», Libro homenaje a Claus Roxin, 1995, p. 394; A. Heitzer, Punitive Sanktionen in Europaischen Gemeinschaftrecht, Heidelberg, 1997, pp. 128-130.

${ }^{28}$ No obstante hay hay autores que dudan de esas especiales dificultades de prueba, vid. H. Otto, Die Strafbarkeit von Unternehmen und Verbänden, 1993, p. 8. En el Derecho penal español, conforme a la regla del artículo 31 bis 2 del Código Penal, no es precisa la individualización de la concreta persona actuante o dirigir el procedimiento contra ella para que pueda exigirse responsabilidad de la persona jurídica. En el Derecho administrativo sancionador español, de hecho, hasta la fecha en la práctica se venía empleando ese mismo criterio, si bien, prescindiendo de toda referencia a un Derecho penal de las personas jurídicas que hasta hace muy poco simplemente no existía. 
para la empresa y dentro de sus competencias es visto como su personificación o encarnación. Por otra, una actuación defectuosa de los trabajadores, y no sólo de los dirigentes, es un indicio de la culpabilidad del propio gerente o administrador de la persona jurídica. Finalmente, el estándar respondeat superior es una manera de impulsar a los que tienen responsabilidades directivas a tomar medidas que impidan la comisión de ilícitos por parte de todos los sujetos físicos que se integran en la persona jurídica y no sólo la de los que ocupan tales puestos de dirección ${ }^{29}$.

En segundo lugar, como alternativa al modelo de respondeat superior se ha manejado lo que se conoce como alter ego o identification theory, consistente en estimar que la responsabilidad de la empresa se desencadena sólo por actos u omisiones cometidos por los órganos o representantes legales, esto es, formalmente cualificados para actuar en nombre o por cuenta de la persona jurídica ${ }^{30}$. En

${ }^{29}$ Vid., por todos, Richard S. Gruner, Corporate criminal liability and prevention, op. cit., § 1.2, 1-8. Entre esas medidas se suele destacar la necesidad de una política de selección del personal y entrenamiento del personal eficaz: J. Gobert; M. Punch, Rethinking corporate crime, op. cit., p. 55. Algún autor añade, asimismo, la necesidad de las grandes empresas de delegar funciones, hasta el punto de que los altos o medios directivos puede que no tengan relación directa con la operación que desencadena el hecho imputado a la empresa; Kathleen B. Brickey, Corporate criminal liability, op. cit. $\S 3.04$.

${ }^{30}$ Hasta donde alcanzo, entiendo que es el modelo brasileño (ceñido a la materia mediomabiental), ya que conforme al artículo 3 de la Ley 9605 de 12 de febrero de 1998 «As pessoas jurídicas serão responsabilizadas administrativa, civil e penalmente conforme o disposto nesta Lei, nos casos em que a infração seja cometida por decisão de seu representante legal ou contratual, ou de seu órgão colegiado, no interesse ou benefício da sua entidade». No hay, pues, referencia alguna a los trabajadores de la persona jurídica. Aunque las opiniones no siempre son firmes en la adscripción del sistema inglés, dependiendo del delito en concreto, habitualmente se estima que pertenece a este modelo, sobre todo a raíz de la decisión Tesco Supermarkets Ltd. V 
definitiva, se requiere poseer desde el punto de vista jurídico una función dirigente en el seno del ente colectivo, en la medida en que se estima que tales órganos o personas son el alter ego de la sociedad. De esta forma no es suficiente con un cúmulo de actos defectuosos, sin una decisión por parte de quien es formalmente competente, para desencadenar la responsabilidad social ${ }^{31}$. Tal criterio, estimamos, da lugar a múltiples problemas. Sintéticamente, por una parte, semejante diseño favorece la impunidad ya que basta para eludir la responsabilidad con nombrar formalmente como representante a

Nattrass. Se trataba de un asunto que resulta más propio del Derecho administrativo sancionador en sistemas como el español o el alemán: el director de un gran almacén de una cadena nacional de supermercados autorizó vender productos a un precio que no fue el publicitado y donde se estimó que tal sujeto no representaba la cabeza pensante y la voluntad de la empresa, excluyéndose, pues, la responsabilidad de esta última (vid., por muchos, J. Gobert; M. Punch, Rethinking corporate crime, op. cit., pp. 59 y ss. en cuanto al sistema inglés en general y 62-3 en lo que al caso citado en particular respecta; C. Wells, Corporations and Criminal Responsibility, op. cit., p. 109, si bien se manifiesta muy crítica, al tiempo que manifiesta cómo el sistema se va matizando en el sistema inglés y canadiense. De alguna manera, se trata del sistema que se sigue en la $O W i G, \S 30$; al respecto, vid., por todos, N. Bosch, Organisationverschulden in Unternehmen..., op. cit., p. 46, crítico con el sistema en pp. ss.; K. Rogall, Karlsruher Kommentar zum Gesetz über Ordnungswidrigkeiten, 3 Auf., München, 2006, § 30, 1 y 51. A favor del sistema, vid. M. Brender, Die Neueregelung der Verbandstäterschaft im Ordnungswidrigkeitenrecht, 1989, p. 105; K. Volk, «Zur Bestrafung von Unternehmen», JZ, 1993, 9, p. 433, donde proporciona alguna ulterior referencia bibliográfica; vid., asimismo, la información que proporciona G. Heine, Die strafrechtliche Verantwortlichkeit von Unternehmen, op. cit., p. 221. En España, entiendo que éste es el criterio defendido por S. Bacigalupo Sagesse, Responsabilidad penal de las personas jurídicas, op. cit., p. 390, p. 394, etc. al requerir que sean las personas físicas que representen a la persona jurídica, conforme a sus estatutos las que actúen; de la misma autora «Responsabilidad penal de las personas jurídicas», Curso..., op. cit., p. 92.

${ }^{31}$ Vid., por ejemplo, Kathleen B. Brickey, Corporate criminal liability, op. cit.§3.01. 
quien de hecho no ejerce funciones directivas. Por otra, deja sin resolver los problemas que se plantean en los casos de sociedades de hecho o en formación. Asimismo, no responde correctamente a la compleja estructura que presentan las grandes sociedades contemporáneas en las que resulta difícil la delimitación de la responsabilidad, ya que, por un lado, ésta se encuentra difuminada y, por otro, las decisiones se toman muchas veces en niveles intermedios ${ }^{32}$. Tampoco parece requerirse la propia responsabilidad del sujeto individual, lo que no es conciliable con alguno de los fines perseguidos con la sanción de las personas jurídicas ${ }^{33}$. Por último, adolece del defecto de restringir excesiva e innecesariamente la responsabilidad, como se desprende del ejemplo de los trabajadores que llevan a cabo un vertido contaminante sin aprobación de los directivos de la empresa que negocian la venta de los desechos a otra sociedad $^{34}$.

${ }^{32}$ Así también vid. Pamela H. Bucy, «Why Punish?,...», op. cit., 1290; E. Colvin, «Corporate Personality and Criminal Liability», 6 Crim. L.F. 1, (1995), 15; John C. Cofee Jr., «Corporate criminal liability. An introduction and comparative survey», Criminal responsibility of legal and collective entities (A. Eser, G. Heine, B, Huber, eds.), Freiburg I Br., 1999, pp. 16-7. Refleja tal opinión, en España, por ejemplo, M.J. Guardiola Lago, Responsabilidad penal de las personas jurídicas..., op. cit., p. 52. Excluía de lege ferenda expresamente la responsabilidad en caso de actuación de simples operarios S. Bacigalupo Sagesse, La responsabilidad penal de las personas jurídicas..., op. cit., p. 394.

${ }^{33} \mathrm{G}$. Heine, Die strafrechtliche Verantwortlichkeit von Unternehmen, op. cit., p. 225.

${ }^{34}$ Sostiene A. Nieto Martín que los sistemas de responsabilidad como el descrito en el texto normalmente van asociados a modelos de responsabilidad objetiva (strict liability offences). En contra interpreto que en la doctrina administrativista española se manifiesta, entre otros, B. Lozano Cutanda, «La responsabilidad de la persona jurídica en el ámbito sancionador administrativo...», op. cit., p. 227. 
Finalmente, en tercer lugar, además de los dos anteriores, existen modelos mixtos conforme a los cuales sólo tienen capacidad para comprometer penal o administrativamente a la empresa quienes se encuentran en su estructura en una posición dirigente, la cual puede oscilar según los diversos sistemas ${ }^{35}$. Las ventajas de tal modelo

${ }^{35}$ Se viene indicando que es el sistema que sigue el Model Penal Code $§ 2.07$, el cual ha sido adoptado por múltiples estados sin apenas modificaciones. Sin embargo, a pesar de ello, pocos estados han adoptado tan restrictiva definición conformándose la mayor parte con la capacidad de tener un poder de supervisión sobre otros empleados, lo que se encuentra en línea con el significado literal del término «management»; vid. Cristopher Green, «Punishing Corporations: The Food-Chain Schizophrenia in Punitive Damages and Criminal Law», 87 Neb. L. Rev. 197 (2008), 204. Se ha dicho que se trata de un modelo que es adoptado por múltiples ordenamientos jurídicos de influencia anglosajona, como los derechos inglés, canadiense, israelí y australiano, y tiene un origen civilista: al respecto, vid., por ejemplo, M. Kremnitzer, K. Ghanayim, «Die Strafbarkeit von Unternehmen», op. cit., p. 541 y 549 y ss. (aunque ya hemos señalado que el sistema inglés más bien se adscribe a la teoría de la representación); C. Wells, Corporations and Criminal Responsibility, op. cit., p. 118; en cuanto al Derecho australiano y de Nueva Zelanda, vid. Eric Colvin, "Corporate Personality and Criminal Liability», op. cit., 2; con carácter general, vid. los detalles que proporcionan C. Gómez-Jara Díez, La responsabilidad penal de las empresas en los EEUU, 2006, pp. 50 y ss.; J.M. Zugaldía Espinar, La responsabilidad penal de empresas..., op. cit., pp. 168-9 en cuanto a la normativa europea que sigue tal criterio; M.J. Guardiola Lago, Responsabilidad penal de las personas jurídicas..., op. cit., p. 50; A. Nieto Martín, La responsabilidad penal de las personas jurídicas..., op. cit., pp. 89 y ss.; en general, en cuanto a los países europeos que se decantan por este modelo, vid. también H. Engels, Unternehmenvorsatz und Unternehmensfahrlässigkeit im europaischen Kartellrecht, Berlin, 2002, p. 115. Entiendo que se trataría, asimismo, del modelo adoptado en el Derecho de la competencia de la Unión Europea y en otros de sus ámbitos. Así, podemos citar, por ejemplo, la Decisión Marco 2005/222/JAI de 24 de febrero de 2005, relativa a los ataques contra sistemas de información, cuyo artículo 8.1 dispone que «Cada Estado miembro adoptará las medidas necesarias para que a las personas jurídicas se les puedan exigir responsabilidades por las infracciones 
tendrían que ver con una limitación de la responsabilidad social frente a la amplitud con la que viene configurado el estándar respondeat superior $^{36}$. Desde nuestra perspectiva, no obstante, presenta como inconveniente el que ignora que muy frecuentemente la acción, $u$ omisión, llevada a cabo por un empleado que desarrolle un papel subordinado en la estrucutura social sólo adquiere sentido como hecho de la empresa y sus consecuencias son vistas socialmente como tal hecho de empresa. Tal dato no es baladí si se considera que uno de los fines de la punición de las personas jurídicas radica, precisamente, en la prevención general positiva. Por otra parte, el criterio que adopta, entre otros, el Model Penal Code es difícil de conciliar con la idea de que la responsabilidad penal y administrativa de las personas jurídicas se establece también para estimular modos de gestión empresarial que eviten la comisión de delitos (lo que incluye la política de personal, su selección, supervisión y control).

mencionadas en los artículos 2, 3, 4 y 5, cuando dichas infracciones sean cometidas en su beneficio por cualquier persona, actuando a título particular o como parte de un órgano de la persona jurídica, que ostente un cargo directivo en el seno de dicha persona jurídica basado en: a) un poder de representación de dicha persona jurídica, o b) una autoridad para tomar decisiones en nombre de dicha persona jurídica, o c) una autoridad para ejercer un control en el seno de dicha persona jurídica». Resulta significativo como en la jurisprudencia del TJCE en relación con las infracciones comunitarias se ha impuesto un criterio funcional económico, conforme al cual debe considerarse a toda persona que actúe por cuenta de la empresa y que tenga capacidad para comprometerla jurídicamente, en definitiva, cualquier persona que actúe en nombre de la entidad o que tenga poder de decisión de hecho o de derecho; vid. L. Zúñiga Rodríguez, Bases para un modelo de imputación de responsabilidad..., op. cit., p. 144; A. Nieto Martín, «¿Hacia un espacio sancionador administrativo común?», Revista Penal 28, 2011, p. 142.

${ }^{36}$ Por ello, es apoyado, por ejemplo, por K. Tiedemann, «La responsabilidad penal de las personas jurídicas», op. cit., pp. 124-5. 
Desde nuestro punto de vista, a la vista de lo expuesto, existen poderosas razones para adoptar en el marco administrativo sancionador un modelo próximo al estándar respondeat superior. En suma, probablemente, si el Derecho positivo no impone un criterio alternativo, y en todo caso de lege ferenda, debería afirmarse la tipicidad de la conducta de la persona jurídica por la verificación de infracciones administrativas siempre que cualquiera de las personas enmarcadas en la estructura societaria lleven a cabo comportamientos, activos u omisivos, que sean subsumibles en el correspondiente tipo. Ulteriormente, como veremos, debería exigirse que tales acciones $\mathrm{u}$ omisiones sólo puedan adquirir sentido en el contexto social, dato este último de carácter valorativo, (un vertido, la defraudación de impuestos de la sociedad, actos contrarios a la competencia..., etc. sólo pueden comprenderse si se asocian a la persona jurídica; carecen de explicación como actos propios de la persona física).

En ese contexto, quizá pueda ser significativo poner de relieve que el criterio expuesto es el aceptado, con matices, por el artículo 31 bis del Código Penal español ${ }^{37}$. Por consiguiente, desde un punto de vista estrictamente español, adoptar tal modelo en el ámbito de las infracciones administrativas es la idea más coherente con la perspectiva conforme a la cual ambos sectores del ordenamiento

${ }^{37}$ Literalmente el citado artículo 31 bis. CP dispone que «En los supuestos previstos en este Código, las personas jurídicas serán penalmente responsables de los delitos cometidos en nombre o por cuenta de las mismas, y en su provecho, por sus representantes legales y administradores de hecho o de derecho. En los mismos supuestos, las personas jurídicas serán también penalmente responsables de los delitos cometidos, en el ejercicio de actividades sociales y por cuenta y en provecho de las mismas, por quienes, estando sometidos a la autoridad de las personas físicas mencionadas en el párrafo anterior, han podido realizar los hechos por no haberse ejercido sobre ellos el debido control atendidas las concretas circunstancias del caso». 
jurídico presentan idéntica naturaleza jurídica ${ }^{38}$. Formulado en otros términos, si el Código Penal español ha solucionado la cuestión expuesta en los términos expresados, no debería optarse por soluciones alternativas en el marco del Derecho administrativo sancionador, al menos no sin un sólido criterio que sustente esa desviación.

\subsection{Especial referencia al caso de la actuación de trabajadores, carentes de poder de decisión.}

Conforme al planteamiento desarrollado hasta este momento, cualquier persona que actúe en el ámbito societario debería poder comprometer penal o administrativamente a la persona jurídica, incluido el personal subordinado, carente de poder de decisión ${ }^{39}$. La cuestión que surge, sin embargo, es si está justificado el que éstos últimos tengan idéntica capacidad para determinar la responsabilidad de la persona jurídica que quien se encuentra en una posición directiva. Desde nuestra perspectiva, como hemos destacado, en la

${ }^{38}$ Posición que, reiteramos, es sin duda mayoritaria y que suscribimos plenamente; con caracter general, vid. M. Gómez Tomillo; I. Sanz Rubiales, Derecho administrativo sancionador. Parte general, op. cit., Capítulo 2.5.

${ }^{39}$ De hecho, es posible encontrar alguna resolución jurisprudencial que apoya el punto de vista expuesto, Asimismo, cabe hacer referencia a la STS de 20 de mayo de 1992 (RJ 1992, 3655), F. 4o, que, con cita de numerosas sentencias afirma que «... la doctrina jurisprudencial dominante, con algunas vacilaciones.... ha venido afirmando con rotundidad la responsabilidad administrativa de las entidades bancarias y crediticias, por la falta de utilización negligente, por parte de sus empleados, de las medidas de seguridad instaladas en cumplimiento de las disposiciones antes reseñadas...». Vid., asimismo, en sentido próximo, en la STS de 31 de octubre de 1994 (RJ 1994\7977), Fto. Jco. 3ä, con cita de las SSTS de 25 mayo y 21 septiembre 1992 (RJ 1992\3723 y RJ 1992\6844 ) y la de 3 mayo 1993 (RJ $1993 \backslash 3698)$. 
medida en que los trabajadores que actúan en el marco de la persona jurídica son percibidos socialmente como la persona jurídica misma, no está justificado el prescindir de la posibilidad de imponer una sanción a la entidad cuando el sujeto realmente actuante sea, precisamente, un trabajador carente de poder decisorio. Sin embargo, simultáneamente, estimamos que procede compensar de alguna manera el minus que supone el que la actuación se haya llevado a cabo por quien desempeña un rol secundario en el contexto socientario por un plus de exigencia. Desde esa perspectiva puede ser razonable la solución adoptada por el Código Penal español a la que nos referiremos a continuación ${ }^{40}$.

El Código Penal español, en cuanto a tales personas subordinadas sin poder de dirección, ha requerido un plus para que la empresa, sociedad, etc. se vea comprometida jurídico-penalmente por su actuación u omisión. Ese plus sería la ausencia sobre ellos de «el debido control» por parte de los administradores de hecho o de derecho (vid. artículo 31 bis.1, párrafo segundo) ${ }^{41}$. Se trata de un

${ }^{40}$ Se trata de un criterio, por una parte, aceptable de lege ferenda en el marco del Derecho penal, o administrativo sancionador, en los ordenamientos que todavía no han aprobado la responsabilidad penal de las personas jurídicas. Por otra, es aplicable, analógicamente al Derecho administrativo sancionador español, en la medida en que supone una restricción del alcance de la responsabilidad de la persona jurídica y no una extensión.

${ }^{41}$ La cuestión, sustancialmente, no cambia en el Proyecto de Ley de reforma del Código Penal, actualmente en trámite en el Parlamento, donde la nueva redacción proyectada, artículo 31 bis. 1 b), dispone que «De los delitos cometidos, en el ejercicio de actividades sociales y por cuenta y en beneficio directo o indirecto de las mismas, por quienes, estando sometidos a la autoridad de las personas físicas mencionadas en el párrafo anterior, han podido realizar los hechos por haberse incumplido por aquéllos los deberes de supervisión, vigilancia y control de su actividad atendidas las concretas circunstancias del caso». Se plantea en este contexto 
requisito que, en ocasiones, ha sido utilizado por la jurisprudencia y doctrina alemanas en el marco, precisamente, de las infracciones administrativas ${ }^{42}$. Obviamente la cuestión que se presenta es si tal

la cuestión de quién debe ejercer ese debido control. Al respecto, ha destacado Silva Sánchez que el texto legal no define el círculo de garante o garantes de la de supervisión de la conducta del subordinado J.M. Silva Sánchez, «La responsabilidad penal de las personas jurídicas en Derecho español», Criminalidad de empresa y compliance, (J.M. Silva Sánchez dir.), Barcelona, 2013, p. 22. En mi opinión cualquiera esa función debe desempeñarla cualquiera que no se encuentre en esa posición de subordinación, esto es, los administradores de hecho o de derecho, lo cual, a su vez, guarda relación con el alcance que se otorgue a esas categorías, de lo que nos ocupamos a continuación; entiendo en el mismo sentido A. Urruela Mora, «La introducción de la responsabilidad penal de las personas jurídicas en Derecho español en virtud de la LO 5/2010: perspectiva de lege lata», Estudios Penales y Criminológicos XXXII, 2012, p. 430; B. del Rosal Blasco, «La delimitación típica de los llamados hechos de conexión...», op. cit., p. 90.

${ }^{42}$ En ese contexto se ha llegado a exigir la verificación de que con el debido control se hubiese impedido el resultado con una probabilidad rayana en la certidumbre, requisito que, ocasionalmente, aparece en la literatura y jurisprudencia alemanas en el marco de las infracciones administrativas: G. Heine, Die strafrechtliche Verantwortlichkeit von Unternehmen, op. cit., p. 224, con cita de Cramer en el Karlsruher Kommentar a la Ordnungswidrigkeitgesetz en relación con el en relación con el § $130 \mathrm{OWiG}$; un punto de vista próximo, vid. J.M. Silva Sánchez, «La responsabilidad penal de las personas jurídicas...», op. cit., p. 22. Alguna construcción más matizada indica que la empresa, «en su globalidad», debe encontrarse en situación de situación de impedir el hecho (H-J. Hirsch, «Strafrechtliche Verantwortlichkeit von Unternehmen», ZStW107, 1995, p. 323); en otras ocasiones se habla de «dirigibilidad» (Steuerbarkeit) del curso de los acontecimientos; vid., por ejemplo, N. Bosch, Organisationverschulden in Unternehmen..., op. cit., p. 59. Semejante criterio, procedente de la teoría de los delitos de comisión por omisión, resulta cuestionable en la medida en que introduce un juicio hipotético que debería abandonarse en el marco de un Derecho penal o administrativo sancionador que juzgue por lo que efectivamente acaeció y no por lo que hubiera podido suceder. Debería bastar, pues, con acreditar la ausencia de 
requisito, debe trasladarse a las infracciones y administrativas. Desde nuestra perspectiva, no cabe duda de que la respuesta debe ser afirmativa ${ }^{43}$. De lege lata, en España, es concebible la extrapolación de tal requisito, por medio de un razonamiento analógico, en la medida en que siempre implicará una restricción de la responsabilidad y no una ampliación, al tiempo que no parece conveniente la atomización de los regímenes penal y administrativo. De lege ferenda, en otros sistemas distintos al español, en la medida en que puedan aceptar la idoneidad del modelo propuesto.

Aceptado el planteamiento desarrollado, resulta central tanto para el Derecho penal, como para el Derecho administrativo sancionador, delimitar el alcance de unas y otras categorías. Esto es, se trataría de acotar quién tiene poder para determinar directamente la responsabilidad jurídico-penal o administrativa de la entidad ${ }^{44}$, y cuándo, por el contrario, se requiere para ello que la conducta vaya acompañada de ese elemento adicional, cual es la ausencia de debido control. En cuanto a este último grupo de individuos, desde nuestra perspectiva, son dos los aspectos que deben considerarse.

control y que el resultado sobrevino causalmente bien por la acción de un agente de la empresa, bien conectado causalmente con el foco de riesgo sobre el que era garante la empresa en el caso de que se trate de un delito o infracción administrativa omisiva. ${ }^{43}$ Ya advertía Rebollo Puig que no se trata «de invocar simplemente un genérico deber de vigilar a los empleados, como ocurre en el Derecho Civil para justificar suficientemente la responsabilidad patrimonial de los empresarios por actos de aquéllos, sino otro deber impuesto por el ordenamiento que exige tomar precauciones para que no sea transgredido en el ejercicio de la actividad empresarial incluyendo el control, a estos específicos efectos, de los que intervienen en ella» (Potestad sancionadora, alimentación y salud pública, op. cit., p. 769).

${ }^{44}$ Lo que el artículo 31 bis del Código Penal español denomina «administradores de hecho o de derecho y representantes legales». 
Desde un punto de vista positivo, debe entenderse que se requiere alguna clase de vinculación jurídica entre la persona física actuante, de carácter subordinado, y la persona jurídica, sea por medio de una relación laboral, arrendamiento de servicios o empresa de trabajo temporal. Por lo tanto, a título de ejemplo, apenas puede dudarse de que la fraudulenta declaración de impuestos efectuada por un asesor fiscal contratado por la empresa a tal efecto debería generar la responsabilidad de la sociedad ${ }^{45}$.

Desde un punto de vista negativo, entendemos que debe excluirse del concepto de persona subordinada a los mandos intermedios, los cuales deben ser considerados como administradores a efectos tanto jurídico-penales como administrativo-sancionadores ${ }^{46}$.

${ }^{45}$ Con más detalle vid. nuestro trabajo, Introducción a la responsabilidad penal de las personas jurídicas, op. cit., VI, 5.3; sigue literalmente nuestro criterio la Circular 1/2011 de la Fiscalía General del Estado, p. 46.

${ }^{46}$ Entiendo que no cabe duda de que un mando o directivo intermedio es, a efectos del artículo 31 bis del Código Penal español, un administrador de hecho. En el mismo sentido, J.M. Silva Sánchez, «La responsabilidad penal de las personas jurídicas...», op. cit., p. 23; J.L. de la Cuesta Arzamendi, «Responsabilidad penal de las personas jurídicas en el Derecho español», op. cit., A-05:12; otro criterio, B. del Rosal Blasco, «La delimitación típica de los llamados hechos de conexión...», op. cit. pp. 57 y ss., especialmente p. 65; J.L. Díez Ripollés, «La responsabilidad penal de las personas jurídicas. Regulación española», op. cit., p. 21; B. Feijoo Sánchez, «La responsabilidad penal de las personas jurídicas», op. cit., p. 95; del mismo autor, «Las características básicas de la responsabilidad penal de las personas jurídicas en el Código Penal español», op. cit., p. 95. En el Proyecto de Ley en discusión en el Parlamento, estimo que se deja la cuestión algo más clara cuando en el artículo 31 bis 1 proyectado. Se dispone que «En los supuestos previstos en este Código, las personas jurídicas serán penalmente responsables: a) De los delitos cometidos en nombre o por cuenta de las mismas, y en su beneficio directo o indirecto, por sus representantes legales o por aquellos que actuando individualmente o como integrantes de un órgano de la persona jurídica, están autorizados para tomar decisiones en nombre de la persona 
Las razones para ello son múltiples. Como ya hemos destacado, tales sujetos, mandos o directivos intermedios, al menos en parcelas concretas de la empresa, poseen capacidad de tomar decisiones socialmente relevantes ${ }^{47}$. Aceptada alternativa o cumulativamente la responsabilidad penal o administrativo-sancionadora de las personas jurídicas, parece que lo coherente es adoptar un modelo que permita la efectiva sanción de éstas, haciendo realidad los fines perseguidos con tales penas o sanciones ${ }^{48}$. Por otra parte, si, como ha sido destacado, una de las características de las sociedades actuales es la división del trabajo, la descentralización y la atomización de las responsabilidades, no parece suficiente con que la empresa adopte una estructura organizativa compleja para restringir el alcance de su responsabilidad penal, o administrativa, frente a lo que acaece en estructuras sociales más simples ${ }^{49}$. La conclusión es, en fin, clara si se adopta el test característico de las construcciones dogmáticas alemanas, en virtud del cual se requiere constatar la disponibilidad de poderes o facultades que

jurídica u ostentan facultades de organización y control dentro de la misma».

${ }^{47}$ Ejemplifica con los directores de una sucursal bancaria, A. Urruela Mora, «La introducción de la responsabilidad penal de las personas jurídicas...», op. cit.. p. 430. ${ }^{48} \mathrm{Si}$ se limita el alcance del concepto de administrador de hecho se aproxima el sistema español al modelo propugnado por la teoría de la representación, cuyos problemas hemos destacado supra y que conduce a muy pocas condenas por delitos graves, John C. Cofee Jr., «Corporate criminal liability. An introduction and comparative survey», op. cit., p. 17.

${ }^{49}$ Vid., por ejemplo, como K. Volk, subraya el problema que se presenta en las grandes estructuras empresariales con un peso fuerte de las decisiones por parte de órganos de dirección medios y bajos, donde la alta dirección se limita a tomar medidas relativas al presupuesto y la fijación de objetivos «Zur Bestrafung von Unternehmen», op. cit., p. 433. 
permiten la ofensa de los bienes jurídicos ${ }^{50}$. No puede dudarse de que esa potencialidad ofensiva la poseen los directivos intermedios que no son formalmente administradores sociales. En definitiva, en nuestra opinión, debe considerarse que los mandos o directivos intermedios, a efectos jurídico-penales, o administrativo-sancinadores, deberían tener capacidad para comprometer directamente, sin necesidad de ulteriores requisitos a la persona jurídica para la que trabajan ${ }^{51}$. Tal idea permite ensanchar este último concepto no sólo hacia arriba, incluyendo a quienes materialmente ejercen altas funciones de dirección, sino también hacia los niveles inferiores de la persona jurídica, englobando a quienes efectivamente tienen capacidad para tomar decisiones que potencialmente resulten peligrosas o lesivas de bienes jurídicos, independientemente de que en el caso concreto se haya omitido o no ejercer sobre ellos el debido control.

Cuestión diversa es la de la carga de la prueba de ese «debido control». Se trata de una cuestión que dependerá de la ubicación

${ }^{50} \mathrm{Al}$ respecto, vid., por todos, P. Faraldo Cabana, Los delitos societarios. Aspectos dogmáticos y jurisprudenciales, Valencia, 2000, p. 147.

${ }^{51}$ De hecho, como hemos destacado, conforme al Model Penal Code (§ 2.07) se requiere para imputar responsabilidad a la persona jurídica que el delito fuese «authorized, requested, commanded, performed, or recklessly tolerated by the board of directors or by a high managerial agent». Se ha discutido, precisamente el alcance de la idea de «high managerial agent». El § 2.07(4)(c lo define como «an officer of a corporation or an unincorporated association, or, in the case of a partnership, a partner, or any other agent of a corporation or association having duties of such responsibility that his conduct may fairly be assumed to represent the policy of the corporation or association». Sin embargo, a pesar de ello, pocos estados han adoptado tan restrictiva definición conformándose la mayor parte con la capacidad de tener un poder de supervisión sobre otros empleados, lo que se encuentra en línea con el significado literal de «management»; vid., por ejemplo, Cristopher Green, «Punishing Corporations...», op. cit., 204. 
sistemática de tal elemento. $\mathrm{Al}$ respecto se pueden proporcionar dos posibilidades. Por una parte, cabe sostener que es un elemento del tipo de todos los delitos o infracciones administrativas susceptibles de ser cometidos por personas jurídicas cuando el hecho de conexión sea verificado por una persona con un papel subordinado. Por otra, se puede pensar que se trata de un elemento integrante de la culpabilidad, caracterizada esta última, siguiendo la conocida construcción de TIEDEMANN, como defectuosa organización ${ }^{52}$. No se trata de algo sólo de índole teórica. Si se sostiene el primer punto de vista, como todos los elementos del tipo, debe acreditarse por la acusación en el proceso penal, o por la Administración en el procedimiento

${ }^{52}$ Asumimos con ello, sin que podamos detenernos en los detalles, la conocida construcción de Tiedemann, conforme a la cual debe hablarse de culpabilidad de las personas jurídicas por «defecto de organización»: K. Tiedemann, «Die "Bebüssung" von Unternehmen...», op. cit., p. 1172; del mismo autor, y entre otras obras, «Responsabilidad penal de las personas jurídicas», Anuario de Derecho penal 1996, J. Hurtado del Pozo (dir.), www.unifr.ch/derechopenal/anuario/96k196html, no 15 y ss.; vid. el desarrollo que efectúa su discípulo M. Brender, vid. Die Neueregelung der Verbanstäterschaft..., op. cit., particularmente pp. 105 y ss. Coincide matizadamente con él H. Otto, Die Strafbarkeit von Unternehmen und Verbänden, op. cit., p. 29, quien sostiene que lo decisivo es si la acción del órgano conforme a deber o una organización de estas características, la introducción de medidas de precaución o control, hubiera podido evitar o disminuir el peligro para el bien jurídico. No obstante, este último punto de vista supone la introducción de un cuestionable juicio hipotético. Una construcción que estimo próxima es la de Hirsch, para el que no es suficiente con que la persona jurídica se organice de forma que no se produzca ningún delito, sino que el hecho hubiera podido evitarse mediante una mejor selección de personal, de los órganos, politica de negocios, etc. («La cuestión de la responsabilidad penal de las personas jurídicas», op. cit., pp 1122 y ss.). Esta última construcción se basa, asimismo, en juicios hipotéticos que deben restringirse al máximo en Derecho sancionador, sobre la base del principio in dubio pro reo. En general, sobre el estado de la discusión, nos remitimos a nuestro trabajo Introducción a la responsabilidad penal..., op. cit., pp. 97 y ss. 
administrativo, y justificarse razonadamente en la sentencia o resolución administrativa su concurrencia. Por el contrario, si se estima que es un elemento de la culpabilidad, cabe presumirlo, con carácter iuris tantum, como es habitual con todos los elementos integrantes de la culpabilidad ${ }^{53}$. Por consiguiente, en este último caso

${ }^{53}$ Afirmado el concepto de culpabilidad, en los términos expuestos, como defecto de organización, entendemos que se trata de un juicio que no está presente de forma automática en los casos en los que se verifique la realización de los elementos objetivos del tipo. Muy al contrario, puede excluirse la responsabilidad sancionatoria, cuando la persona jurídica acredite una correcta organización cara a la evitación de delitos, o infracciones administrativas. No compartimos, pues, el criterio del propio Tiedemann conforme al cual la empresa no puede librarse de la sanción mediante la prueba de una organización eficiente. Como tampoco entendemos la concepción de su discípulo M. Brender, conforme al cual la empresa sólo puede eximirse de responsabilidad probando que el hecho de conexión no existe M. Brender, Die Neueregelung der Verbandstäterschaft im Ordnungswidrigkeitenrecht, op. cit., p. 117. Se trata de uno de los puntos de la construcción de Tiedemann que más críticas ha suscitado; vid., por ejemplo, N. Bosch, Organisationverschulden in Unternehmen..., op. cit., p. 58, n. 201; en España, entre otros, B. Feijoo Sánchez, quien subraya la fusión de la culpabilidad con elementos objetivos del tipo (Sanciones para empresas..., op. cit., pp. 70 y ss.); A. Nieto Martín, Fraudes comunitarios..., p. 208; C. Gómez-Jara, La culpabilidad de penal de la empesa, pp. 153 y ss.; H. Achenbach, «Sanciones con las que se pueden castigar a las empresas...», op. cit., p. 405. Como es conocido, en los Estados Unidos no se admite a nivel federal la llamada due diligence defence; no obstante, se pone de manifiesto que la sanción económica se puede modular en función de la existencia de tal organización diligente orientada a impedir la comisión de delitos, hasta el punto de llegar a una aminoración de la multa de hasta el 90\% (vid. John C. Cofee Jr., "Corporate criminal liability. An introduction and comparative survey», op. cit., p. 11). Sin embargo en ese país, también hay propuestas doctrinales que permiten excluir la responsabilidad penal a las empresas acreditando la ausencia de defectos organizativos, especialmente en el caso de delitos cometidos por sus empleados; vid., por ejemplo, note «Developments in the Law-Corporate crime: regulating corporate behavior through criminal sanctions», 92 Harvard L. R. 1227 (1979); Pamela H. 
incumbiría al acusado o al infractor probar que los hechos acaecieron pese a que se desplegó el debido control sobre el trabajador. Esta última perspectiva es la que se corresponde con los postulados dogmáticos de los que parte este trabajo ${ }^{54}$, por lo que concierne su prueba a quien

Bucy, «Ccorporate criminal liability: When does it make sense?», op. cit., 1442 y passim; Ellen S. Podgor, "A New Corporate World Mandates a "Good Faith" Affirmative Defense», 44 Am. Crim. L.R. 1537 (2007). Esa prueba de diligencia se admite en el Model Penal Code $§ 2.07$ (5), si bien añade la cláusula «this paragraph shall not apply if it is plainly inconsistent with the legislative purpose in defining a particular offence». Incluso en los derechos francés y japonés en los casos de hechos cometidos por operarios con relevancia jurídico penal para la empresa, aun presumiéndose la vulneración del deber de control empresarial, se admite prueba en contrario (vid. G. Heine, Die strafrechtliche Verantwortlichkeit von Unternehmen, op. cit., p. 224, donde destaca que si el ámbito de responsabilidad fue delegado por completo, sin posibilidad de control por parte de la empresa, prácticamente se descarta la posibilidad de tal prueba en contrario en el derecho japonés; vid.,asimismo, p. 231). Finalmente, en relación con el derecho inglés, vid. J. Gobert; M. Punch, Rethinking corporate crime, op. cit., pp. 100-102, donde pone de manifiesto que en ese ordenamiento jurídico resulta admisible a «defence of due diligence».

${ }^{54}$ Sobre la cuestión, vid. M. Gómez Tomillo, Introducción a la responsabilidad penal de las personas jurídicas, op. cit., Capítulo 11; ha seguido nuestro criterio de que se puede presumir y de que compete a quien lo alega su prueba, la Circular de la FGE 1/2011, p. 48. En el Derecho administrativo sancionador destaco lo expuesto por Rebollo Puig, con el que coincidimos plenamente: «la regla general es que las empresas pueden ser sujetos activos de infracciones propias por consecuencias d einfracciones de sus empleados y que, además, ello supone normalmente su culpabilidad. Esto último, no obstante, puede ser desvirtuado probando una diligencia completa en el cumplimiento del deber, así como en la vigilancia de los empleados en cuanto a tal deber, o que el trabjador actuo contraviniendo abiertamente las instrucciones del empresario sin posibilidad de control por parte de éste. Pero nótese que esta expresión se sitúa en el terreno de la culpabilidad. Si finalmente no se sanciona no será porque no se considera que que el infractor sea el empleado o porque éste deba responder de la infracción ajena, sino porque no 
alega haber ejercido ese debido control. Conviene no perder de vista que el requisito de la omisión del debido control es un elemento más que se exige en el caso de actuación de trabajadores comprometedora de la entidad, no presente cuando de administradores o representantes legales se trata ${ }^{55}$. En consecuencia, parece coherente al tratarse de esa exigencia añadida, someterla a requisitos de prueba más exigentes.

En la medida que estimamos que se trata de una cuestión de culpabilidad, no entramos en ella en este trabajo, circunscrito a la imputación de infracciones administrativas, o delitos, a personas jurídicas y que, por tanto, se mueve en el ámbito de la tipicidad.

\section{La exigencia de que el hecho de conexión aparezca externamente como hecho de empresa.}

Conforme a lo expuesto, no debería ser suficiente con la verificación de un hecho objetivamente típico por parte de los administradores, representantes legales o trabajadores de una persona jurídica para imputar a esta última un delito o una infracción administrativa. Como con mucha razón expone ZUGALDÍA ESPINAR, es preciso además que tal hecho aparezca en el contexto social, se visualice socialmente, como obra de la persona jurídica ${ }^{56}$, que

concurre culpabilidad en la empresa», M. Rebollo Puig, Potestad sancionadora, alimentación y salud pública, op. cit., p. 771.

${ }^{55}$ Como expresa A. Galán Muñoz, «la ampliación del número de sujetos que pueden convertir a la persona jurídica en responsable de las conductas delictivas que cometan se va a ver en cierta medida compensada por el incremento de los requisitos materiales que se van a exigir para que ello suceda», «La responsabilidad penal de la persona jurídica tras la reforma de la LO 5/2010... », op. cit., p. 520.

${ }^{56}$ J.M. Zugaldía Espinar, La responsabilidad penal de las empresas...., op. cit.., p. 350. 
socialmente sólo tenga sentido como acto de empresa. Sólo así se legitima, sólo así tiene sentido preventivo, la sanción a la persona jurídica.

Entiendo que a esa idea responde el modelo español de responsabilidad penal de las personas jurídicas (en nuestra opinión trasladable por analogía a las infracciones administrativas). En efecto, en este último se exige que la acción del administrador, representante legal o trabajador haya tenido lugar «en nombre o por cuenta» $\mathrm{y}$ «en provecho» de la persona jurídica (vid. artículo 31 bis.1 CP español) ${ }^{57}$. Se trata de expresiones que han generado ya una amplia polémica en lo que concierne a su alcance, cuya reproducción excedería de las posibilidades de este trabajo ${ }^{58}$. Baste, pues, aquí con poner de manifiesto que, desde nuestra perspectiva, cada una de las expresiones citadas encierra un significado distinto ${ }^{59}$.

${ }^{57}$ Entiendo que nada muy diferente, por otra parte del sistema brasileño en materia medioambiental, en la medida en que el artículo 3 de la Ley 9605 de 12 de febrero de 1998 «As pessoas jurídicas serão responsabilizadas administrativa, civil e penalmente conforme o disposto nesta Lei, nos casos em que a infração seja cometida por decisão de seu representante legal ou contratual, ou de seu órgão colegiado, no interesse ou benefício da sua entidade». Mutati, mutandis, pues, las reflexiones del texto son válidas en este último ordenamiento jurídico.

${ }^{58}$ Ampliamente, por todos, vid., por ejemplo, A. Urruela Mora, «La introducción de la responsabilidad penal de las personas jurídicas...», op. cit., pp. 426 y ss.; A. Galán Muñoz, «La responsabilidad penal de la persona jurídica tras la reforma de la LO 5/2010...», op. cit., pp. 531 y ss.; J.L. Díez Ripollés, «La responsabilidad penal de las personas jurídicas...», op. cit., pp. 21 y ss.; M. Gómez Tomillo, Introducción a la responsabilidad penal de las personas jurídicas, op. cit., pp. 82 y ss.

${ }^{59}$ Otro criterio puede verse en J.M. Zugaldía Espinar, La responsabilidad penal de las empresas..., op. cit., p. 277 quien estima que las expresiones «en nombre» y «por cuenta» son sinónimas; en ese mismo sentido, interpreto a la doctrina dominante: $\mathrm{S}$. Bacigalupo Sagesse, «Los criterios de imputación de la responsabilidad penal...», op. cit., p. 4; J.G. Fernández Teruelo, «Algunas consideraciones críticas sobre el nuevo 
En primer lugar, la Ley exige que la persona física actúe «en nombre o por cuenta» de la jurídica. Se trata de un requisito formulado alternativamente. Probablemente ha entenderse que cuando la Ley exige que el sujeto obre «en nombre de la empresa» se refiere a los casos en los que aquel actúa, u omite hacerlo, dentro de lo que es su competencia aparente. Con otras palabras, cuando un tercero, un espectador objetivo, razonablemente creería que el agente poseía autorización de la empresa, sobre la base de su posición en ésta ${ }^{60}$. De ello se deduce que los excesos del sujeto actuante $\mathrm{u}$ omitente, su actuación en contra de lo que era la política social, o incluso contra las órdenes expresas no excluyen automáticamente la responsabilidad

modelo de responsabilidad penal de las personas jurídicas...», op. cit., p. 67; vid., asimismo, C. Gómez Jara, «La responsabilidad penal de las personas jurídicas en la reforma del Código Penal», op. cit., p. 6; V. Gómez Martín, Comentarios al Código Penal, op. cit, p. 133.

${ }^{60}$ En términos que interpreto muy próximos vid. L. Zúñiga Rodríguez, «Societas delinquere potest», La reforma penal de 2010, -L. Zúñiga et al. coords.-, Salamanca, 2011, p. 13; asimismo, en la literatura norteamericana, vid. J. Gobert; M. Punch, Rethinking corporate crime, op. cit., p. 57, donde se recoge jurisprudencia de aquel país. 
social $^{61}$. Sigue existiendo un hecho de empresa imputable a ésta ${ }^{62}$, la cual, sin embargo, puede eximirse de la pena si en el caso concreto no hubo culpabilidad, por lo que no hay responsabilidad objetiva ${ }^{63}$.

${ }^{61}$ Rechaza que la extralimitación implique ausencia de responsabilidad de la persona jurídica la Circular 1/2011, p. 41. Por el contrario, C. Gómez Jara rechaza que concurra el requisito de actuar en nombre o por cuenta de la persona jurídica cuando se trate de una extralimitación de la persona física actuante, exigiendo, pues, que se trate de la implementación de una política empresarial («La responsabilidad penal de las personas jurídicas en la reforma del Código Penal», op. cit., p. 6). Asimismo, para V. Gómez Martín la expresión legal en nombre o por cuenta de la persona jurídica excluye la responsabilidad de la sociedad, cuando su representante legal o administrador no cometa el delito en tal condición, esto es, cuando lo haga actuando al margen de su función de representación o administración (Comentarios al Código Penal, op. cit., p. 133); en igual sentido, vid. J.M. Silva Sánchez, «La responsabilidad penal de las personas jurídicas...», op. cit., 2013, pp. 26 y ss.; B. del Rosal Blasco, «La delimitación típica de los llamados hechos de conexión...», op. cit., pp. 85-86; B. Feijoo Sánchez, «La responsabilidad penal de las personas jurídicas», op. cit., p. 98; A. Díaz Gómez, «El modelo de responsabilidad criminal de las personas jurídicas tras la LO 5/2010», Revista Electrónica de Ciencia Penal y Criminología, 13-08, 2011, p. 3. En la literatura del los Estados Unidos en la línea del texto, vid. Kathleen B. Brickey, Corporate criminal liability, op. cit., § 3.01; no obstante, en algunos casos excepcionales en los tribunales norteamericanos se ha llegado a excluir tal responsabilidad (id., Kathleen B. Brickey, § 3:08); J. Gobert; M. Punch, Rethinking corporate crime, op. cit., p. 57.

${ }^{62}$ Aun cuando los fundamentos de la responsabilidad civil y penal son diversos, el criterio expuesto, al menos, resulta coherente con la regulación de la responsabilidad civil derivada del delito y, concretamente, con el artículo 120.4, donde se hace responsable a la persona jurídica por los excesos del dependiente.

${ }^{63}$ Otro criterio, sin embargo, J.G. Fernández Teruelo, «Algunas consideraciones críticas sobre el nuevo modelo de responsabilidad penal de las personas jurídicas...», op. cit., p. 64. 
Por el contrario, cuando la Ley se refiere a la actuación «por cuenta» de la persona jurídica ${ }^{64}$ supone una actuación dentro de lo que es realmente su ámbito competencial. Supone que el sujeto se encontraba formalmente habilitado para actuar, u omitir hacerlo, como lo hizo.

Por otra parte, el Código Penal español ha introducido la exigencia de que se actúe «en provecho» de la persona jurídica ${ }^{65}$. Desde nuestro punto de vista, la expresión en provecho debe ser entendida objetivamente, aunque no como resultado de la acción del sujeto físico. Concretamente entiendo que se está requiriendo la objetiva tendencia de la acción a conseguirlo. Se estaría requiriendo la constatación de la idoneidad $\mathrm{ex}$ ante de la conducta de la persona física para que la persona jurídica obtuviese alguna clase de beneficio asociado a aquélla, aunque tal beneficio no fuese directo o inmediato, por ejemplo, por ser una posibilidad futura que, finalmente, no acaeciese ${ }^{66}$. Como en el caso

${ }^{64}$ Se sigue con ello, al menos parcialmente, el criterio del Model Penal Code, el cual en la $\S 2.07$ requiere que el sujeto (agent) actúe, «in behalf of the corporation»; asimismo, aparece en el art. 121.3 del Código Penal Francés («pour compte»).

${ }^{65} \mathrm{Ha}$ habido quien ha estimado que se trata de un requisito vinculado al tipo subjetivo; N. González-Cuéllar Serrano; A. Juanes Peces, «La responsabilidad penal de las personas jurídicas y su enjuiciamiento en la reforma de 2010. Medidas a adoptar antes de su entrada en vigor», La Ley 7501, 2011, p. 10; críticamente, con razón, vid. S. Bacigalupo Sagesse, «Los criterios de imputación de la responsabilidad penal de los entes colectivos y de sus órganos de gobierno (arts. 31 bis y $129 \mathrm{CP}$ )", op. cit., p. 4 y n. 38; en general crítica con este requisito, vid. de la misma autora S. Bacigalupo Sagesse, Comentarios al Código Penal, op. cit., art. 31 bis, a). ${ }^{66}$ Así lo manifestábamos en nuestra Introducción a la responsabilidad penal de las personas jurídicas, op. cit. (n. 7), pp. 84 y ss. y especialmente p. 86. Acoge literalmente nuestro criterio la Circular de la Fiscalía General del Estado 1/2009, p. 43. Interpreto hoy en este sentido a J.M. Zugaldía Espinar, "Societas delinquere potest... », op. cit., p. 3, cuando sostiene que la acción debe tender al beneficio siendo 
de las personas físicas, para verificarlo debería recurrirse al criterio de un espectador objetivo. En suma, la Ley requiere que se trate de un hecho de empresa que carezca de sentido, que sea, pues, incomprensible desde otra perspectiva.

Una vez más, por idénticas razones a las que venimos exponiendo, entendemos que tanto la Administración en primera instancia y, ulteriormente, los Tribunales de justicia, deberían mantener el criterio del Código Penal a la hora de imputar una infracción administrativa a una persona jurídica.

\section{BIBLIOGRAFÍA}

ACHENBACH, H., «Sanciones con las que se pueden castigar a las empresas y a las personas que actúan en su nombre en el Derecho alemán», Libro homenaje a Claus Roxin, 1995.

ARTAZA VARELA, O., La empresa como sujeto de imputación de responsabilidad penal, 2012.

BACIGALUPO SAGESSE, S., La responsabilidad penal de las personas jurídicas, 1998.

BACIGALUPO SAGESSE, S., «Los criterios de imputación de la responsabilidad penal de los entes colectivos y de sus órganos de gobierno (arts. 31 bis y 129 CP)», La Ley 7541, 2011.

BACIGAluPO SAGESSE, S., Comentarios al Código Penal (M. Gómez Tomillo, dir.), 2a ed., Valladolid, 2011, art. 31 bis, a).

BACIGALUPO SAGESSE, S., «La responsabilidad penal de los entes colectivos: societas delinquere non potest», Libro homenaje al Profesor Luis Rodríguez Ramos, Valencia, 2013.

indiferente que éste se produzca o no; B. Feijoo Sánchez, «La responsabilidad penal de las personas jurídicas», op. cit., p. 99. 
BACIGALUPO, E., «Responsabilidad penal y administrativa de las personas jurídicas y programas de "compliance" (A propósito del Proyecto de reformas del Código Penal de 2009)», La Ley 7442, 2009.

Bajo Fernández, M., «Vigencia de la responsabilidad penal de las personas jurídicas en el derecho sancionador español», Tratado de responsabilidad penal de las personas jurídicas, 2012,.

BAJO FERNÁNDEZ, M.; Bacigalupo Sagesse, S., Derecho penal económico, 2a ed., Madrid, 2010.

BOSCH, N., Organisationverschulden in Unternehmen, 2002.

BRENDER, M., Die Neueregelung der Verbandstäterschaft im Ordnungswidrigkeitenrecht, 1989.

BRICKEY, Kathleen F., Corporate criminal liability, 2 ed., 1992.

BUCY, Pamela H., «Why Punish? Trends in Corporate Criminal Prosecutions», 44 Am Crim. L. Rev. 1287 (2007).

COFEE JR., John C., «Corporate criminal liability. An introduction and comparative survey», Criminal responsibility of legal and collective entities (A. Eser, G. Heine, B, Huber, eds.), Freiburg I Br., 1999.

COLVIN, E., «Corporate Personality and Criminal Liability», 6 Crim. L.F. 1, (1995). Cuesta Arzamendi, J.L. de la, «Responsabilidad penal de las personas jurídicas en el Derecho español», Revue électronique de l'AIDP, 2011.

DANNECKER, G., «Zur Notwendigkeit der Einführung kriminalrechtlicher Sanktionen gegen Verbände», GA 2001.

DÍAZ GÓMEZ, A., «El modelo de responsabilidad criminal de las personas jurídicas tras la LO 5/2010», Revista Electrónica de Ciencia Penal y Criminología, 13-08, 2011. DÍEZ RIPOLLÉS, «La responsabilidad penal de las personas jurídicas. Regulación española», InDret 1-2012.

ENGELS, H., Unternehmenvorsatz und Unternehmensfahrlässigkeit im europaischen Kartellrecht, Berlin, 2002.

FARALDO CABANA, P., Los delitos societarios. Aspectos dogmáticos y jurisprudenciales, Valencia, 2000.

FEIJOO SÁNCHEZ, B., Sanciones para empresas por delitos contra el medio ambiente (Presupuestos dogmáticos y criterios de imputación para la intervención del Derecho penal contra las empresas), Madrid, 2002.

FEIJOO SÁNCHEZ, B., «La responsabilidad penal de las personas jurídicas», Estudios sobre las reformas del Código Penal operadas por las LO 5/2010 de 22 d ejunio y 3/2011, de 28 de enero (J. Díaz Maroto, dir.), 2011. 
FEIJOO SÁNCHEZ, B., «Las características básicas de la responsabilidad penal de las personas jurídicas en el Código Penal español», Tratado de responsabilidad penal de las personas jurídicas, 2012.

FERNÁNDEZ TERUELO, J.G., «La responsabilidad penal de las personas jurídicas en el Código Penal español: una visión crítica», Revista Jurídica de Castilla y León 25, 2011.

GALÁN MUÑOZ, A., «La responsabilidad penal de la persona jurídica tras la reforma de la LO 5/2010: entre la hetero-y la autorresponsabilidad», Nuevos instrumentos jurídicos en la lucha contra la delincuencia económica y tecnológica, (C.M. Romeo Casabona; F. Flores Mendoza Eds.-), 2012.

GALLARDO CASTILLO, M.J., Los principios de la potestad sancionadora. Teoría y práctica, 2008.

GOBERT, J.; Punch, M., Rethinking corporate crime, 2003.

GÓMEZ MARTín, V., Comentarios al Código Penal (M. Corcoy Bidasolo; S. Mir Puig, dirs.), Valencia, 2011, art. 31 bis.

GÓMEZ TOMILLO, M., «Imputación objetiva y culpabilidad en el Derecho penal de las personas jurídicas», Revista Jurídica de Castilla y León 25, 2011.

GÓMEZ TOMILLO, M.; Sanz Rubiales, I., Derecho administrativo sancionador. Parte general. Teoría general y práctica del Derecho penal administrativo, 3a ed., 2013.

GÓMEZ-JARA DÍEZ, C., «Autoorganización empresarial y autorresponsabilidad empresarial», RECPC 08-05.

GÓMEZ-JARA DÍEZ, C., La culpabilidad penal de la empresa, Madrid, Barcelona, 2005.

GÓMEZ-JARA DÍEZ, C., La responsabilidad penal de las empresas en los EEUU, 2006.

GONZÁLEZ-CUÉLLAR SERRANO, N.; Juanes Peces, A., «La responsabilidad penal de las personas jurídicas y su enjuiciamiento en la reforma de 2010. Medidas a adoptar antes de su entrada en vigor», La Ley 7501, 2011.

GREEN, Cristopher, "Punishing Corporations: The Food-Chain Schizophrenia in Punitive Damages and Criminal Law», 87 Neb. L. Rev. 197 (2008).

GRUNER, Richard S. Corporate criminal liability and prevention, New York, (updated 2010).

GUARDIOLA LAGO, M.J., Responsabilidad penal de las personas jurídicas y alcance del artículo 129 del Código Penal, Valencia, 2004. 
HEINE, G., Die strafrechtliche Verantwortlichkeit von Unternehmen, von individuellem Fehlverhalten zu kollectiven Fehlentwicklungen, insbesondere bei Grossrisiken, 1995.

HEITZER, A., Punitive Sanktionen in Europaischen Gemeinschaftrecht, Heidelberg, 1997.

HIRSCH, H-J., «La cuestión de la responsabilidad penal de las asociaciones de personas», ADPCP 1993.

HIRSCH, H-J., «Strafrechtliche Verantwortlichkeit von Unternehmen», ZStW107, 1995.

KREMNITZER, M.; Ghanayim, K., «Die Strafbarkeit von Unternehmen», ZStW, 113, 2001.

LOZANO CUTANDA, B., «La responsabilidad de la persona jurídica en el ámbito sancionador administrativo (a propósito de la STC 246/1991», RAP129, 1992

LOZANO CUTANDA, B., «Persona jurídica, sujeto activo responsable de las infracciones administrativas», Diccionario de sanciones Administrativas (B. Lozano Cutanda, dir.), Madrid, 2010.

MAYOR MENÉNDEZ, P., «Sobre la responsabilidad conjunta de las personas jurídicas y sus administradores en el Derecho administrativo sancionador (especial referencia al Mercado de Valores», REDA 87, 1995.

NIETO MARTÍN, A., «¿Hacia un espacio sancionador administrativo común?», Revista Penal 28, 2011, p. 142.

NIETO MARTÍN, A., La responsabilidad penal de las personas jurídicas: un modelo legislativo, 2008.

NIETO, A., Derecho administrativo sancionador, 5a edición, 2012

OTTO, H., Die Strafbarkeit von Unternehmen und Verbänden, 1993.

POLLACK, Barry J., «Time to stop living vicariously: a better approach to corporate criminal liability», 46 Am. Crim. L. Rev. 1393.

RANDO CASERMEIRO, P., La distinción entre el Derecho penal y el Derecho administrativo sancionador. Un análisis de política jurídica, Valencia, 2010.

REBOLLO PUIG, M., Potestad sancionadora, alimentación y salud pública, Madrid, 1989.

ROBLES PLANAS, R., «¿Delitos de personas jurídicas?», InDret 2-2006.

ROGALL, K., Karlsruher Kommentar zum Gesetz über Ordnungswidrigkeiten, 3 Auf., München, 2006, § 30.

ROSAL BLASCO, B. del, «La delimitación típica de los llamados hechos de conexión, en el Nuevo artículo 31 bis no 1 del Código Penal», CPC 103, 2011. 
SILVA SÁNCHEZ, J.M., «La responsabilidad penal de las personas jurídicas en el Convenio del Consejo de Europa sobre cibercriminalidad», Cuadernos de Derecho Judicial 9, 2002

SILVA SÁNCHEZ, J.M., «La responsabilidad penal de las personas jurídicas en Derecho español», Criminalidad de empresa y compliance, (J.M. Silva Sánchez dir.), Barcelona, 2013.

TIEDEMANN, K., «Die "Bebüssung” von Unternehmen nach dem 2 Gesetz zur Bekämpfung der Wirtschaftskrimimalität», NJW41, 1988.

TIEDEMANN, K., «Responsabilidad penal de las personas jurídicas», Anuario de Derecho penal 1996 (http://www.unifr.ch/ddp1/derechopenal/anuario/an_1996_07.pdf)

TRUG, G., «Zu den Folgen des Einführung eines Unternehmensstrafrechts», Wistra 7, 2010.

URRUELA MORA, A., «La introducción de la responsabilidad penal de las personas jurídicas en Derecho español en virtud de la LO 5/2010: perspectiva de lege lata», Estudios Penales y Criminológicos XXXII, 2012.

VOLK, K., «Zur Bestrafung von Unternehmen», JZ, 1993, 9.

WELLS, C., Corporations and Criminal Responsibility, 1993.

ZUGALDÍA ESPINAR, J.M., «Societas delinquere potest (Análisis de la reforma operada por la LO 5/2010 de 22 de junio)», La Ley penal, 76, 2010.

ZUGALDÍA ESPINAR, J.M., La responsabilidad penal de empresas, fundaciones y asociaciones, Valencia, 2008.

ZÚÑIGA RODRÍGUEZ, Bases para un modelo de imputación de responsabilidad penal de las personas jurídicas, 2001.

ZÚÑIGA RODRÍGUEZ, L., «Societas delinquere potest», La reforma penal de 2010, -L. Zúñiga et al. coords., Salamanca, 2011. 